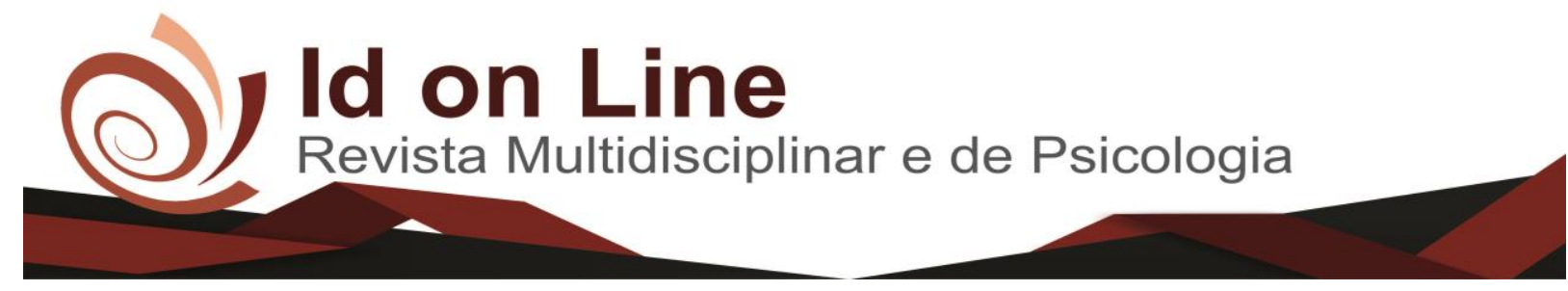

Comment

\title{
Impactos da Utilização das Tecnologias no Processo de Aprendizagem das crianças
}

Flávia Maria Pereira ${ }^{1}$;

\begin{abstract}
Resumo: No mundo globalizado, a atual sociedade vive inserida em um emaranhado de informações onde as notícias se propagam em frações de segundos, devido à velocidade pela qual as mensagens, textos e hipertextos são divulgados na Internet. Encontra-se descrito neste trabalho o processo das tecnologias educacional como vem acontecendo esse novo jeito de ensinar, a parceria que vem sendo feita entre alunos e professores, a tecnologia na educação e na vida das crianças, abordamos os pontos positivos e negativos, o mesmo aponta desgaste com o uso excessivo de jogos e seus objetivos encontra-se aqui também a desnecessidade das redes sociais na vida das criança e suas influências negativas, ao se exporem, buscamos assim conscientizar sobre o uso deste meio, não banalizá-las mas encontra formas, de ser uma ferramenta benéfica.
\end{abstract}

Palavras -chave: Tecnologias. Aprendizagem. Impactos.

\section{Impacts of the Technology Usage on Children Learning Process}

\begin{abstract}
In the globalize world, today's oscite is embude in a tangle of information where the news spreads in fractions of seconds, due to the speed at which messages, texts and hypertexts are disseminated on the Internet. The process of educational technologies is described in this work, as it is happening this new way of teaching, the partnership that is being made between students and teachers, technology in education and in the life of children, we discuss the positives and negatives, the same points out wear and tear with the excessive use of games and their goals is also here the need of social networks in children's lives and their negative influences, when exposing themselves, we seek to raise awareness about the use of this environment, not to trivialize them but find ways , to be a beneficial tool.
\end{abstract}

Keywords: Technologies. Learning. Impacts.

\section{Introdução}

A tecnologia no mundo atual vem sendo motivos de diversos questionamentos entre pais e professores, e isso levou a investigar sobre esses impactos das mídias na vida da criança, esta inquietação partiu da mudança de comportamento de um dos meus alunos, desde então começou a apresenta posturas que não era natural dele, agressão física e verbal contra os colegas o mesmo passou a responder mal os professores e a mentir dizendo que estava sentindo dores para assim ir para casa, depois de uma conversa com sua mãe, ela afirmou que a criança estava muito 
agressiva e viciada no tablet, e que já não queria mais fazer seus deveres, fazia uma grande confusão quando ela não deixava ele fazer o uso.

O problema que norteou esse estudo foi: como lidar com essas crianças diante das tecnologias? Não se deve banalizar as tecnologias da vida das crianças, mais buscar estratégias para utilizá-las, como uma ferramenta pedagógica.

Resgatar as brincadeiras tradicionais, para o ambiente escolar fazendo pesquisas com uso do computador dessas brincadeiras. Pois a mesma vem trazendo, possibilidades de serem utilizadas como ferramentas de ensino, no intuito de deixa as aulas mais prazerosas, sem se desfazer da tecnologia.

Esse trabalho tem como objetivo geral verificar até que ponto pais e professores estão atentos na utilização dos aparelhos tecnológico no processo de ensino e aprendizagem das crianças, nisso conscientizar os mesmo da sua responsabilidade de educar para a tecnologia, examinando outros métodos como a ludicidade e as atividades realizadas em grupos.

Nessa mesma linha podemos refletir o que traz o artigo em si, o que compete as escolas diante das tecnologias educacionais, nesse processo continua que vem passando por diversas mudanças no novo jeito de ensinar oferecida por os aparelhos eletrônicos, e de fato vem a contribuir se utilizado da maneira correta, mas não devemos deixa de ressalta que por outro lado a mesma apresenta malefícios no desenvolvimento da criança. Esses meios trazem uma insegurança na utilização nas salas de aula, as crianças já, chegam na escola como uma bagagem bem cheia de informações, que são adquiridas em casa, os mesmos já ensinam ao adulto o que a alguns tempos atrás era um cenário diferente, também é importante deixa claro que isso não é um ponto negativo. O segundo subtema, destacamos os jogos violentos que por sua vez, vem deixando, muitas crianças agressivas e mudado de comportamento, de uma forma preocupante, nos faz refletir os males que esses jogos oferecem.

Buscamos destacar pontos negativos que as redes sócias, causa na vida das crianças, as mesmas ficam expostas, desde de pequenas, sendo uma falha grave dos pais, essas crianças, ao ter um facebook, pode abrir páginas impróprias para sua idade, conversa com pessoas estranhas, passar informações da família. Refletindo sobre esses pontos é possível, entende que as crianças estão perdendo sua infância. 


\section{Recorte da história sobre as tecnologias educacionais e o seu processo no ambiente escolar}

Desde da pré-história a tecnologia se faz presente na vida da humanidade, a mesma ao longo tempo vem passando por um processo continuo de inovar, trazendo consigo maneiras de comunicação em tempo real.

No ano de 1877 surgiu o primeiro aparelho eletrônico capaz de registra e produzir sons que era o Fonógrafo uma criação de Thomas Edison mais que só veio chegar no Brasil alguns anos depois do seu surgimento e logo depois foram surgindo outros aparelhos, o rádio, televisão, telefone, celular, computador, etc. Até então só quem possuía esses aparelhos era quem tinha uma vida estável, o que mudou com o passar do tempo, com esses avanços tecnológicos passaram a ser consumir cada vez mais pelo o homem, esses aparelhos. Tendo uma contribuição na vida social, e pessoal deixando o homem expostos e dependente dela, tendo o papel de facilitadora, nas empresas, escolas entre outros departamentos.

Percebe-se que os aparelhos já não são mais usados apenas para se comunicar com quem está longe, e trazer informações, mas sua função também é ser uma ferramenta de estudo na perspectiva de subsidiar, os professores na busca de aulas mais dinamizadas. Hoje há varias tecnologia que dá esse subsídio ao transmitir os conteúdos educacionais, vivemos progressivamente mergulhado nas tecnologias comunicativa a vista disto, as organizações, e docentes, tem a desafio de igualar suas tarefas pedagógicas, aliando-se a tecnologia educacional. Com isso inovando suas instituições, para a tecnologia, desta forma trazendo vantagens para alunos e professores.

Podemos dizer que se há muito tempo o professor era visto como a única fonte de informações. Era considerado o dono do saber, tanto era que havia punições para aqueles alunos que questionasse o professor, sendo uma falta de respeito, deixando assim limitado a sua aprendizagem. Hoje há uma parceria entre aluno e professor, na utilização dos meios tecnológicos o mesmo usado da forma correta transforma-se em uma ponte que liga docente e discente.

Segundo Moran, ele nos diz que:

As tecnologias de comunicação não substituem o professor, mas modificam algumas
das suas funções. A tarefa de passar informações pode ser deixada aos bancos de
dados, livros, vídeos, programas em CD. O professor se transforma agora no
estimulador da curiosidade do aluno por querer conhecer, por pesquisar, por buscar, a
informação mais relevante. Num segundo momento, coordena o processo de
apresentação dos resultados dos alunos. Depois, questiona alguns dos dados
apresentados, contextualiza os resultados, os adapta à realidade dos alunos, questiona 
os dados apresentados. Transforma informação em conhecimento e conhecimento em saber, em vida, em sabedoria o conhecimento com ética. (MORAN, 2009, p.25).

Nota-se que nos dias contemporâneos a capacidade educacional estar claramente fundamentada nas expectativas interminável, de adquirir informações, que pode ser modificado em estudos na enorme capacidade comunicativo, que a mídia disponibilizar, neste cenário ocasionar uma diminuição no figurino recente da educação.

Especialista que buscam entende como acontece o uso dos aparelhos em sala de aula, ressaltam que o uso dos mesmos pode incentivar e beneficiar significativamente o ensino popular. Com essa modernização tecnológica no ambiente escolar, dá suportes não apenas para os professores, mas para os estudantes também, desta forma buscando, conhecimentos que respondam suas necessidades e costumes.

Nesta mesma linha de pensamento, um dos grandes atributos da tecnologia educacional é os caminhos de expectativas de conhecer outros diferentes modos de aprendizagem, trazendo esta realidade a favor da educação, não é preciso modificar esse processo da tecnologia educacional para que desta forma haja modificações essenciais na escola conectada. Compreende-se que para se ter a tecnologia como parceira é necessário que seja utilizada da maneira correta, não espera que as tecnologias por se só, torne-se, benéfica, a mesma contribuir com informações, e possibilidades, deixando o papel do professor de planejar e de fazer a aplicação desses meios corretamente.

Sabe-se que o maior desafio para alguns professores é buscar estratégias para o uso dos aparelhos, por falta de formações continuada, na verdade vivemos e uma sociedade que ainda encontramos de um lado professores ante tecnológico e do outro lado professores que estão tão viciados com a tecnologia que estão perdendo seu lugar em sala de aula e dando espaço somente as informações trazidas pelo o computador, celulares, entre outros aparelhos. As tecnologias abrem leques de oportunidades, para o educador no intuito de criar laços entre os envolvidos, ou seja; alunos e professores.

Como afirma Coutinho, (2011 p 5-22). A escolas e os seus agentes tem de mudar os métodos e técnicas de ensino e pensar em formas eficiente para a sociedade do conhecimento.

No entanto, para que esses métodos de planejar e aplicar tenham resultados satisfatórios é preciso que o professor saiba fazer o uso adequado dos aparelhos que será manuseando, buscando formas significativas nas tecnologias para tornar estimulantes as aulas. 
A inclusão das tecnologias educacional não está ligada apenas em acessa as novas tecnologias. É preciso que as crianças sejam ensinadas a interagir, ou seja; se relacionar, criar, inovar, no sentindo de saber forma seus próprios conhecimentos.

Oliveira nos diz que:

Educar para a comunicação, educação para a mídias educar com os meios educomunicação mídias-educação, caracterizam conceitos que discutem a inclusão das mídias no espaço escolar, tanto no aspecto educacional, como no comunicacional. Refletir um processo educacional que valorize um contato maior com os meios de comunicação é algo que se vislumbra como uma possibilidade, tanto educacional como comunicacional. (OLIVEIRA 2004, p. 29).

Sabe-se que, não será do dia para noite que ocorrerá estas mudanças na Educação. É preciso que haja uma reestrutura de dentro para fora, principalmente dos profissionais inseridos neste contexto.

Ainda dentro deste aspecto, Teruya (2000, p.113) afirma que as tecnologias mediáticas têm um poder de encantamento e sedução dos alunos de crianças a adolescentes, por isso, não é mais possível excluir ou ignorar tais recursos no processo de ensino aprendizagem como fator motivacional no processo educativo da escola.

\section{A influência dos jogos eletrônicos para o desenvolvimento cognitivo das crianças}

Existem vários tipos de jogos, sendo que alguns deles beneficia a criança tendo impactos positivos no seu desenvolvimento, que são os jogos educativos, o nome por si só, já diz sua função, o mesmo não é jogado de apenas um membro deixando os pequenos sozinhos e isolados. O mesmo leva as crianças, a conviver uma com as outras, nisso eles discutir, reinventar, as regras, esse ponto é importante na construção, da autonomia das crianças as mesmas terão que ter uma dinâmica para juntas chegar em uma escolha do espaço onde acontecera, de quem começa, quais os meterias que serão utilizados, ou seja há um entrosamento entre as crianças e com quem ta auxiliando o jogo.

Dentro desta perspectiva podemos destacar que apesar de todos ter o nome de jogos há um grande diferença entre ambos, os dois trazem diferentes informações, no entanto os mais procurados por as crianças e os adolescentes são os violentos, de tiros, guerras e mortes oferecidos principalmente pelos os vídeo games, vem sendo comprovado que essa nova maneira de jogar violenta, podem sim influencia no comportamento das crianças e 
adolescentes, por mais que esses jogos não tenha sido criados para serem usados para modificar o comportamento das crianças.

\begin{abstract}
A violência na mídia não é uma novidade do ambiente digital. Desde tempos imemoriais as crianças têm jogado jogos em que pretendem matar um aos outrospoliciais e ladrões, caubóis e índios, piratas em alto mar, soldados de brinquedos guerreados com outros saldados de brinquedos. As crianças são atraídas pelos revólveres e pela violência. Parte da violência vista na mídia na sociedade modernaseja onlline, na TV ou cinema. (PALFREY/GASSER 2011, p. 248)
\end{abstract}

Dentro desta linha de pensamento, esses jogos levam as crianças a agirem de forma violenta da mesma maneira que lhe é passado, os pequenos que jogam esses tipos de jogos estão cada vez violentas, os jogos acaba que sendo um espelho para elas, a tendência é a cada dia a crianças fica mais dependente dos jogos, o que levaria a sérios problemas, em casa, e principalmente na escola.

Concluir-se que o papel da família e de todos aqueles que convivem com as crianças, é crucial.

\begin{abstract}
Os melhores reguladores da violência da nossa sociedade, seja online ou não são os pais e professores, porque eles são as pessoas mais próximas dos próprios Nativos Digitais. Os pais e os professores passam a maior parte do tempo com as crianças - e assim se espera, tem sua confiança. Como em outros contextos, pais e professores precisam começar entendendo o que seus nativos digitais estão aptos a fazer. A partir daí, é importante estabelecer limites, especialmente para as crianças pequenas nos jogos e na exposição a atividades violentas. (PALAFLE, GASSER. 2011, p.248)
\end{abstract}

Diante dessa violência adquirida pelos os jogos eletrônicos, as crianças ficam exposta a adquirir percas irreparáveis sua maior perca é a infância, e a diminuir o rendimento escolar e eles podem ser vítimas da obesidade, os mesmos passam horas sentadas o que fazem eles não fazer movimentos físicos. Segundo Machado (2011, p.13)

O nível de atividades físicas nas crianças tem demonstrado que a tecnologia tem ganho espaço no mundo das crianças e vem diminuindo a atividade física na infância. As crianças se tornando cada vez mais sedentária por hábitos como assistir televisão, jogar vídeos game, usar computador. (MACHADO 2011, p. 13)

É importante salientar que a infância é o período no qual a criança usa, muito a imaginação, porem com o uso excessivo dos aparelhos eletrônicos tem se perdido essa criatividade, pois os mesmos trazem atividades prontas e acabadas tirando desta forma a autonomia e sua capacidade de criar e se reinventar

Os jogos dos aparelhos eletrônicos são os mais procurados porque trazem propostas que deixam as crianças desafiadas, sem dúvidas esses jogos aquieta as crianças enquanto jogam 
deixando-as concentradas. O que seria um sossego para alguns pais, é motivo de preocupação para outros, as crianças estão cada vez mais violentas e mudado o comportamento progressivamente, isso são influencias negativas em muitos aspectos na vida dos pequenos.

Outros estudos tem confirmado que a agressão física, a agressão verbal e os pensamentos agressivos dos jovens tem correlação com a quantidade de violência na televisão e no cinema que eles assistem regulamente'. Conforme (PALFREY, GASSER 2011)

Nessa mesma linha de pensamento os autores PALFREY / GASSER, ainda afirma que:

A mídia violenta mostra ás crianças como agir agressivamente como tem demonstrado os psicólogos cognitivos e os neurocientistas, as crianças começam a imitar outros seres humanos em muita tenra idade para desenvolver habilidades, incluindo comportamento social (ou antissocial). (PALFREY, GASSER 2011, p. 239, 240)

Nota-se que não devemos de forma nenhuma confundimos jogos educativos com jogos violentos, ficamos atentos quais tipos de jogos nossas crianças estão baixando e qual são de fato os que serão importantes e que levara a crianças a aprender algo que beneficiem eles.

Faz-se necessário os auxílios dos pais com o uso das tecnologias, dando limites, impondo regras, mais assim como o vídeo game a televisão, tablet e outros aparelhos são o que estar substituindo o papel que é da família. A família é um alicerce é a base, ou visamos desta forma ou ficara impossível controla as crianças, nesse mundo tecnológico.

\section{As relações entre a criança, aprendizagem e os ambientes virtuais.}

Desde muito cedo as crianças estão sendo inseridas no mudo tecnológico a mesmas aprendem a manusear os aparelhos eletrônicos com uma facilidade incríveis. Desde seus primeiros dois anos de vida elas já conseguem passar os dedinhos na tela do celular dos seus pais e quando atinge seus três ou quatro anos, já colocam seus desenhos favoritos, isso tá sendo motivo dos pais e de quem ta por perto ficar encantados, com tantas habilidades. Mesmo antes de nasce esses bebes já tem contas e perfil nas redes sócias feitas por seus pais, o que pode se disser que elas já nascem conectadas.

Para alguns pais é natural, posta fotos dos seus filhos na internet, cada momento é marcado, e postado nas horas mais intimas das crianças, os destinos destas fotos podem leva as crianças ao assedio digital, esse assédio é preocupante porque ele é real não é um talvez 
aconteça, essas crianças são ameaçada, obrigadas a mandarem fotos intimas, alguns paris para não expor seus filhos acaba não fazendo a denúncia, algo que pode ser evitado mais não estar sendo, a grande realidade é que os pais vivem ligados a outros interesses. E é impossível não perceber que as redes sociais são cria das por vários tipos de pessoas, de diversas idades e lugares.

Segundo o artigo 17 do Estatuto da criança e do Adolescente:

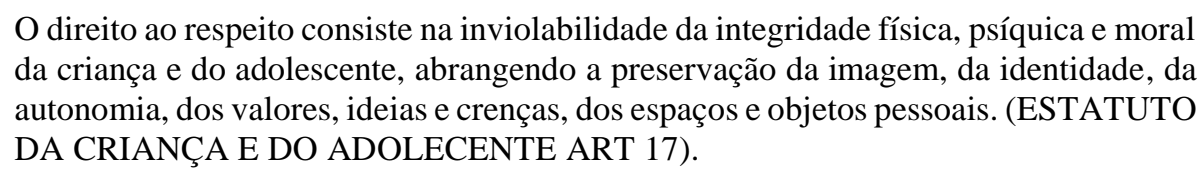

Percebe-se que ao acessarem com frequência, a tendência é fazer com que as crianças perdão seu tempo conectada e esqueçam do mundo real deixando de se comunicar com outras crianças, e mais tarde só terão amigos virtuais. O que levara essas crianças a se isola em casa e também no ambiente escolar.

Ulysses Doria contribuir sobre os riscos que as crianças correm ao se expor e por seres expostas nas redes, com isso ele destaca cinco pontos, que são de muita relevância.

- Exposição a matérias inapropriados: sexual - milhares de fotos, vídeos mostrando toda sorte de perversões - violento, odioso, que encoraje atividades perigosas ou ilegais, ideologias, vulgares etc.

- Agressões físicas: a criança pode passar informações "online" que coloquem em risco a sua segurança assim como a de sua família, por exemplo, fornecendo dados pessoais como seu nome, colégio onde estuda, endereço profissão dos pais características de sua casa, marcando encontros etc.

- Legais e financeiro: há também a possibilidade de cometer crimes como realizar compras de passagens, bens de consumo etc. com o cartão de credito de uma pessoa movimentar aplicações e contas bancária, participar de leiloes, jogar em cassinos virtuais, invadir sites sem permissão etc.

- Oportunidade de experimentar jogos extremamente violentos e inclusive de fazer "download" de versões para demonstração.

- Exposição a uma comunidade praticamente infinita, incontrolável: embora a maioria das pessoas navegando pelo WWW seja bem intencionada, muitas não o são, podendo trata-se de ladrões, assassinos, pedófilos, traficantes e usuários de drogas, 
membros de seitas e ordens diversas de "gangs", que exploram a violência, o sexo, jogos, as drogas e os vícios em geral.

Como se faz notar os pontos abordados por Ulysses Doria é possível que, não fique claro que uma criança não precisa ter um facebook, enquanto criança. Percebe-se que dentro deste contexto podemos destacar que não a pontos positivos nessa prudência dos pais criarem perfil para seus filhos nas redes sociais, mesmo que os pais acompanhe eles nessa etapa, o que pode se dizer que não acontece, terá o dia dela estará sem seus pais por perto, há a idade determina para se ter um perfil, estabelecida até mesmo pelo facebook um dos site mais acessado no mundo todo.

O maior desafio é conscientizar os pais, que por sua vez vivem conectados nas redes sociais, o que nos faz interpreta que querem se livra dos filhos, e os mesmos estão entregando ao mundo virtual a obrigação de educar, acreditam que o melhor presente para uma criança é um tablet, o que a cada dia mais tá separando família e o maior prejudicado disso são as crianças, e os pais acabam perdendo a melhor fase da vida do filho, a infância.

\section{Considerações finais}

Diante das pesquisas podemos destacar como a tecnologia está sendo inserida na vida das crianças, o uso das mesmas nas salas de aulas e não podemos dizer que isso é um ponto negativo, desde de quando não seja substituído o papel do professor, com as tecnologias educacionais.

Hoje em um mundo digital, o maior desafio é educar os pais e futuros pais, de como auxiliar seus filhos diante dessas evoluções, pois a tecnologia cada vez mais vai tomando espaço nas nossas vidas ou dominamos ela ou ela nos domina.

Nessa perspectiva podemos concluir que as crianças estão sendo inseridas no mundo virtual, de uma forma bem rápida, o que levara essas crianças a não terem infância e nem amigos reais, não deixando também de destacar os jogos que as crianças estão jogando, as influencia negativas que eles trazem.

Diante de várias pesquisas podemos concluir quer não devemos banalizar a tecnologia na vida das crianças, mas educar para fazem o uso dos mesmo corretamente, pois assim não termos analfabetos- digitais, e nem crianças viciadas. 


\section{Referências}

COUTINHO, Clara, Lisboa, Eliane. Sociedade da informação, do conhecimento e da aprendizagem: desafios para educação no século XXI. Revista de Educação, vou. XVII, n.1, p 5-22, 2011.

DORIA FILHO, Ulysses. Promoção de segurança da criança e do adolescente frente à mídia. Disponível em: htts://portal.mj.gov.br

MACHADO, Y.L. Sedentarismo e suas consequência em crianças e adolescentes. Muzambinho, 2017.2 Disponível em: http://www.muz.ifsuldeminas.edu.br/attachmenfs/1681_17.pdf acesso em 11 out. 2017.

MORAN, Manuel José; MASETTO, Marcos; BEHRENS, Marilda. Novas Tecnologias e

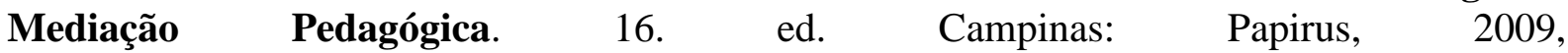
p.1217.Disponívelemhttp://educere.bruc.com.br/arquivo/pdf2013/7646_6015.pdf. Acesso 13 out 2017.

OLIVEIRA, Marcio Romeu Ribas de. O primeiro olhar: Experiente com imagens na Educação Física Escola. 2004. 177f. tese (Mestrado em Educação Física) Centro de Desportos Universidade Federal de Santa Catarina / UFSC. Acessado em 19 out de 2017.

PALFREY, John/ GASSER, Urs. Nascidos na era digital: entendendo a primeira geração de nativos. Porto Alegre: Grupo A, 2011. p, 239-240-248.

https://www.jusbrasil.com.br/topicos/10618111/artigo-17-da-lei-n-8069-de-13-de-julho-de1990. Acesso em 21/10/2017

TERUYA, T. K. Trabalho e educação na era mediática: uma visão sociológica. 2000. 113f. Tese (Doutorado em Educação) - Universidade Estadual Paulista Campus de Marilia. Marilia, 2000.

Como citar este artigo (Formato ABNT):

PEREIRA, Flávia M. Impactos da Utilização das Tecnologias no Processo de Aprendizagem das crianças. Id on Line Revista Multidisciplinar e de Psicologia, 2017, vol.11, n.38, p. 520-529. ISSN: 1981-1179.

Recebido: 01.10.2017

Aceito: 03.11.2017 